\title{
Coordinated Prosumer Transaction based on Load Shifting and Optimization
}

\author{
M.A. Albachrony \\ BPPT Republic of Indonesia - \\ National Institute of Solar Energy, CEA \\ Le Bourget du Lac, France
}

\author{
D.L. Ha, Q.T Tran, A. Brun \\ Smart Grid Laboratory \\ National Institute of Solar Energy, CEA \\ Le Bourget du Lac, France
}

\author{
M. Petit \\ GeePs \\ CNRS, CentraleSupélec, Univ. \\ Paris-Sud, Université Paris-Saclay \\ Gif-sur-Yvette, France
}

\begin{abstract}
Electrical demand in the world especially residential demand is increasing. Instead of building new conventional power plants, distributed generation based on renewable resources are an alternative solution to cope the demand. Simultaneously, government of some countries release their regulation to encourage households be active player in the market. However, in several years now, Feed in Tariff (FiT) is decreased by the regulation. Demand side management strategies especially load shifting are used to reduce the electric cost and trying to handle household satisfaction. To reach the similar goal in the community, coordination of energy management is necessary where customers maximize their self-consumption through PV sharing. Using energy contract and Particle Swarm Optimization it is expected to help the costumers to find their optimal cost, and to reach a maximum self-consumption rate.
\end{abstract}

Index Terms-Demand Side Management, Renewable Energy, Particle Swarm Optimization, Load Shifting.

\section{INTRODUCTION}

Recently, at the worldwide scale, the growth of electricity demand is enormous than before. $30-40 \%$ of total consumption in the world is dominated by residence demand [1]. Supplying electricity from conventional power plant could not meet for it without new investments in power capacities to prevent blackouts. Nevertheless, expansion of new power plant make problems in some sector such as geographic, financial and environment. Distributed generation is the best alternative for helping the supplier in the context fulfilment of electricity needs. In some countries public policies encourage citizens to install their PV system [2]. According to IEA PVPS report, the household has the right for self-consuming and connecting their system to grid. They also offer some benefit from renewable energy installation such as, Feed in Tariff, trading system, tax credit, green certificate and pricing regulation [3].

Investment in PV system secure the household from fluctuation of electricity price. Thanks to the declining price of the renewable energy technologies especially PV panels, the number of PV system users has increased with users able to meet their consumption. Storage system may be needed for consumption at the night in case of excess of energy. They are also expected to become active participants often called as
"Prosumer" in the electricity market where they shared their excess energy to neighbors who plan to obtain cheaper price for electricity, so that it help them to reduce their electricity cost[4]. For improving reliability of power system, Information and Communication Technology (ICT) is taken into account. It is called 'Smart Grid' where it enables both bi-directional communication of information and electricity flow [5][6]. Advance Metering Infrastructure (AMI) along with Home Energy management System (HEMS) has been install in each house in order to manage the self-consumption of the household [6][7].

To support the system, some countries also introduce revenue regulation such as net metering and net billing [3]. Nevertheless, some countries especially in Europe have reduced the Feed in Tariff what can encourage households to maximize their self-consumption with two options such as investment in a storage system or energy management [1]. Selfconsumption is divided in two parts, individual selfconsumption and collective self-consumption. Individual selfconsumption is considered for applying in a household where the electricity is produced and consumed simultaneously [8]. Meanwhile, self-consumption is said collective, when the household as producer shares its electricity with other producers and consumers that are connected through a legal entity, which injection and exit point are on the same voltage (low voltage) loop of the public distribution grid as well as Energy Code Article L315-2

The aim of this paper is to provide a comparison of some strategies to minimize the electricity cost, and to analyze the benefits of the method. The proposed strategies are: (i) original pattern condition (base case without load shifting), (ii) load shifting without optimization, and (iii) load shifting with optimization in bilateral contracts.

\section{OVERVIEW OF ENERGY MANAGEMENT}

\section{A. Demand Side Management}

Demand Management is an important method in the Energy Management, which fulfil the user's satisfaction and at least the minimum satisfaction requirement. It also controls power consumption timing. It is classified in demand management from supply side and demand management from demand side 
(also called Demand Side Management). Generally DSM is also called "Demand Response" and classify in two categories: i) price based, and ii) event based.

TABLE I. TYPE OF APPLIANCES

\begin{tabular}{|c|c|c|}
\hline Type Load & Flexibilities & \\
\hline \multirow{2}{*}{ Flexible } & Shift-able & Washing Machine, Dish Washer, \\
\cline { 2 - 3 } & $\begin{array}{c}\text { Energy } \\
\text { Storage }\end{array}$ & $\begin{array}{r}\text { Water heater, HVAC, Electrical } \\
\text { Car, Refrigerator }\end{array}$ \\
\hline Non-Flexible & Fixed-load & Lamp, , Television, microwave \\
\hline
\end{tabular}

HEMS is one of tool for energy management in households while it manages and controls household's electricity pattern, so that their goal will be achieved. L. Yao et al [9], explain that an HEMS is expected to be highly automated, intelligent, interactive and be able to support high level ICT. Commercial solution of Energy Management System have been developed in the field of control system. Some industrial have been released HEMS technology for residential and offer solutions for energy efficiency and cost reduction where they combine monitoring, controlling, logging, management and alarm system in the device for achieving the goal.

Load shifting is a method for DSM that consists in shifting demand from peak period to off peak period typically when price is lower. This method is used only for rescheduling of appliance, so the total energy consumption of household should not be changed [10]. Load shifting cannot be applied to all appliances, it is only applicable for some appliances that can be reschedule to another period. Therefore, household appliances can be divided in two groups, flexible appliances and non-flexible (fixed loads), see table 1.

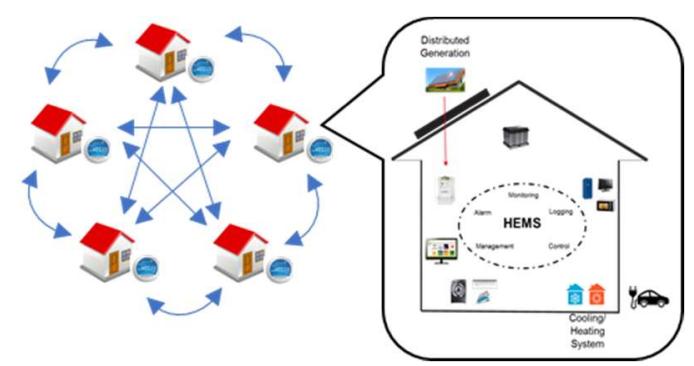

Figure 1. Coordination Energy Management with HEMS

\section{B. Coordinated Management}

Coordinated Managements could be a solution for controlling the appliances without a degradation of user satisfaction (Quality of Life). It is applied in a community withfrom several households that have similar goals. The authors in [5][6][11] explain that coordination is used to allow each household to be a prosumer and reach their satisfaction related to consumption profile and energy production. It also allows the households to create a community and participate in local electricity market. The challenge in this coordination management system is not only to coordinate a particular household's loads to reach their quality of life but also to seek the benefit for their community as a whole.

\section{Particle Swarm Optimization (PSO)}

Kennedy and Ebenhart proposed particle Swarm Optimization (PSO)[12] in 1995 where its algorithm was studied based on the simulation of animal social behaviors, such as bird flock and fish schooling. The PSO method is iconic due to its simplicity of implementation and instantaneously converge to a reasonably good solution. Similar with other population- based optimization method, PSO start with random initialization of a population swarm or particle in the search space. Swarm called particles is initialized randomly to seek optimum solution in an n-dimensional search space.

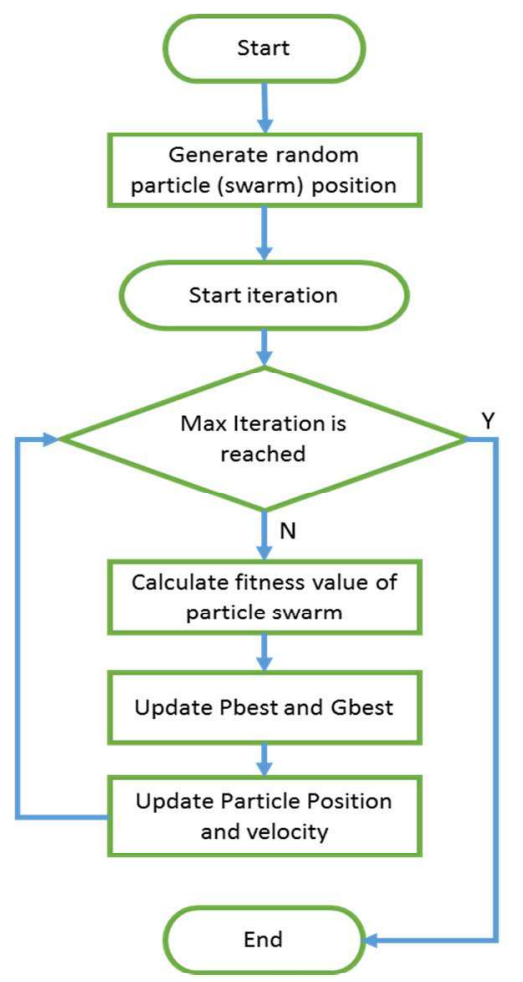

Figure 2. Flowchart of Particle Swarm Optimization

Each particle updates PSO is classified in two approaches such as cognitive and social. First, PSO algorithm set the random value for initial position and maintain population of particles, each of which represents a potential solution to an optimization problem so that Personal best $\left(\mathrm{P}_{\text {best }}\right)$ will be determined. Using iteration $k$, we update $\mathrm{P}_{\text {best }}$ accprding to (1).

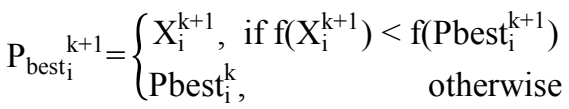

$$
\begin{aligned}
& G_{\text {best }}^{\mathrm{k}+1}=\left\{\begin{array}{l}
X_{\mathrm{i}}^{\mathrm{k}+1}, \text { if } \mathrm{f}\left(\text { Pbest }_{\mathrm{b}}^{\mathrm{k}+1}<\mathrm{f}\left(\text { Pbest }_{\mathrm{i}}^{\mathrm{k}+1}\right)\right. \\
\text { Gbest }^{\mathrm{k}}, \quad \text { otherwise }
\end{array}\right.
\end{aligned}
$$

When the particle is lower than $\mathrm{P}_{\text {best }}$, it will be subsequently updated. Similarly, the Global best also will be updated when 
the new value is lower than previous $\mathrm{G}_{\text {best }}$ as expressed in (2). The flowchart of PSO algorithm is mentioned in fig. 2

\section{PROBLEM FORMULATION}

The problem formulation is based on DSM strategy especially load shifting given in [10]. With this method, scheduling of controlled appliances of household at various time of the day makes load consumption's value closer than the objective load consumption. The objective function of consumption contain the PV energy and fix price, so that the benefit of household to reduce their cost. The Objective function is formulated with minimization as follow

$$
\operatorname{minimize}_{\sum_{\mathrm{t}=1}^{\mathrm{N}}}\left(\text { Powerload }_{(\mathrm{t})}-\text { Objective }_{(\mathrm{t})}\right)^{2}
$$

Where Objective ${ }_{(t)}$ is the value of the objective at the time$\mathrm{t}$, and Powerload is given by

$$
\begin{gathered}
\text { Powerload }_{(\mathrm{t})}=\text { Power }_{(\mathrm{t})}+\text { Connected }_{(\mathrm{t})} \text { - }^{-} \\
\text {Disconnected }_{(\mathrm{t})}
\end{gathered}
$$

With

$$
\operatorname{Power}_{(\mathrm{t})}=\operatorname{InitialLoad}_{(\mathrm{t})}-\text { PVpower }_{(\mathrm{t})}
$$

Where Power $_{(t)}$ is obtained from combination of original consumption power where uncontrollable appliances are activated $\left.\operatorname{InitialLoad}_{(t)}\right)$ with PV production that is generated on the day $\left(\right.$ PVpower $\left._{(t)}\right)$. Meanwhile, Connected $(t)$ is appliances power that are activated at t-time and Disconnected $_{(t)}$ is appliances power that are deactivated optimum solution in an $\mathrm{n}$-dimensional search space at t-time.

To get the best cost for each household, we can formulate the cost on in accordance connectivity with distributed generation where PV energy is shared to household where it is expressed as below

$$
\text { Cost }=\sum_{t=1}^{N} \text { Powerload }_{(t)} \times P
$$

The energy cost is formed from summation of their initial consumption (Powerload) in each time ( $\mathrm{t}$ ) multiply to electricity price $(\mathrm{P})$. The prosumers energy cost to supplier is also given in (6). They also get revenue from their excess energy sold to another household and the supplier. The prosumers reward formula as follow

$$
\text { Reward }=\left(\text { Power }_{\text {injC }} \times\left(\mathrm{P}_{\mathrm{PV}}-\text { Cost }_{\text {dist }}\right)\right)+\left(\text { Power }_{\text {injG }} \times \mathrm{P}_{\mathrm{G}}\right)
$$

Where,

Power $_{\text {injC }}=$ shared power from prosumer to consumer.

Power $_{\text {injG }}=$ shared power to supplier

Cost $_{\text {dist }}=$ Electric distribution cost (depend on DSO)

$\mathrm{P}_{\mathrm{PV}} \quad=$ Price of $\mathrm{PV}$ production

$\mathrm{P}_{\mathrm{G}} \quad=$ Electricity price of supplier
In the consumer side, households consume electricity from the prosumer's shared PV. When the demand in the PV production area is less or equal the shared PV energy and they should pay cost as given in (8). Meanwhile, they also take energy from supplier for the demand in the night. The energy cost as follow

$$
\begin{aligned}
\operatorname{Cost}_{P V(t)} & =\operatorname{Load}_{P V(t)} \times P_{P V(t)} \\
\operatorname{Cost}_{G(t)} & =\operatorname{Load}_{n P V(t)} \times P_{G}
\end{aligned}
$$

Where,

Cost $_{\mathrm{PV}}=$ Cost for PV energy consumption

Cost $_{\mathrm{G}} \quad=$ Cost for Supplier's energy consumption

Load $_{\mathrm{PV}}=$ Load in the PV production area

Load $_{\mathrm{nPV}}=$ Load in outside of PV production area

Instead, the demand in the PV production area is greater than the PV's shared energy, consumer should take energy from supplier to meet their consumption to cover load that is not covered by PV $\left(\operatorname{Load}_{u P V}\right)$. So that, energy cost that is paid by consumers for their demand in the day, as follow

$$
\operatorname{Cost}_{\mathrm{PV}(\mathrm{t})}=\operatorname{Load}_{\mathrm{uPV}(\mathrm{t})} \times \mathrm{P}_{\mathrm{G}(\mathrm{t})}+\operatorname{Load}_{\mathrm{PV}(\mathrm{t})} \times \mathrm{P}_{\mathrm{PV}(\mathrm{t})}
$$

Finding the value of electricity cost, Consumer have to pay overall cost $\left(\operatorname{Cost}_{T}\right)$ for their consumption as follow (11) where it is paid to prosumer and supplier.

$$
\operatorname{Cost}_{\mathrm{T}}=\mathrm{Cost}_{\mathrm{PV}}+\operatorname{Cost}_{\mathrm{G}}
$$

\section{PROBLEM FORMULATION}

Simulation for this problem is applied in Matlab ${ }^{\circledR}$ with data of 10 households without controlled appliances as initial load, controlled appliances as load shifting parameter and PV data. The household and appliances loads is taken from load profile generator software [13].

Specification of household criteria's consist of

1. Couple with Both Work (CBW)

2. Family Two Children with One Work (FTCOW)

3. Family One Child with One Work (FOCOW)

4. Family Two Children with Both Work (FTCBW)

5. Family One Child with Both Work (FOCBW)

6. Retired Couple without Work (RCNW)

7. Single Woman with One Child and Work (SWOCW)

8. Single Man with One Child and Work (SMOCW)

9. Single Woman with Work (SWW), and

10. Single Man with Work (SMW)

Based on number of the household, they could be divided in to two group, prosumer and consumers. PV power connected at each prosumer is $8 \mathrm{~kW}$-peak and storage system is not considered. In load shifting, controlled appliances used in the simulator are washing machine and dish washer. Specification of washing machine is Bosh WAE 28143 2300W for 2 hour 13 minutes. The second controlled appliance is Dish Washer 
NEFF SD6P1F $2110 \mathrm{~W}$ in power and it will run approximately 2 hour and 35 minutes.

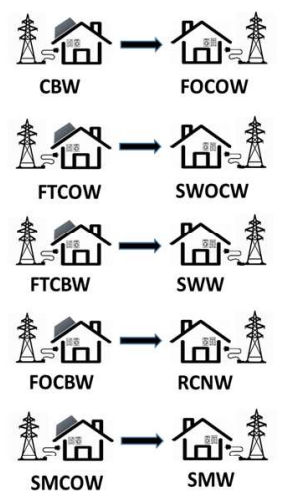

Figure 3. Bilateral contract between prosumer and consumer

The simulation is run for 1-year period and the controlled appliances is assumed to run in every day. The initial activating time is given in table 2, where we assume the households do not apply load shifting. Bilateral contract are considered as shown on Fig. 3, where each household prosumer makes contract with one consumer for sharing energy.

TABLE II. INITIAL OF ACTIVATING TIME OF APPLIANCES IN EACH HOUSEHOLD

\begin{tabular}{|c|c|c|}
\hline \multirow{2}{*}{ Household } & \multicolumn{2}{|c|}{ Activating Time } \\
\cline { 2 - 3 } & Washing Machine & Dishwasher \\
\hline CBW & $18: 00$ & $21: 00$ \\
\hline FTCOW & $11: 00$ & $20: 00$ \\
\hline FOCOW & $09: 00$ & $20: 30$ \\
\hline FTCBW & $18: 30$ & $20: 00$ \\
\hline FOCBW & $19: 00$ & $21: 00$ \\
\hline RCNW & $10: 00$ & $19: 00$ \\
\hline SWOCW & $18: 00$ & $20: 00$ \\
\hline SMOCW & $19: 30$ & $20: 30$ \\
\hline SWW & $20: 30$ & $21: 30$ \\
\hline SMW & $20: 00$ & $22: 30$ \\
\hline
\end{tabular}

The parameter of the financial used for the simulation, such as fix tariff, PV production cost and distribution cost. Furthermore, the bilateral contract is prepared, as shown in Fig. 2, where all household would like to minimize their cost. Fix tariff is $15 \mathrm{c} € / \mathrm{kWh}$ close to the French electricity tariff for residential household. The price of PV production cost is set at $10 \mathrm{c} € / \mathrm{kWh}$ and $3 \mathrm{c} € / \mathrm{kWh}$ for distribution cost, in order to find the different profile of revenue and cost in each household. When there is an excess of energy after bilateral contract, it is sold to the supplier with PV production that is determined by operator and government.

\section{RESULT}

The strategy for DSM defined in the section III using some methods including Particle Swarm Optimization has been applied. Each prosumer and consumer find their best cost using PSO where prosumer 1 cost is $0.21 €$ and consumer $30.281 €$ in first day. The combination of PV and consumption pattern is shown at Fig. 4.a, where prosumer 1 produces excess energy. It will be shared to partner in contract (consumer) and supplier as shown in Fig. 4.b. After that, Prosumer will receive revenue after sharing energy from both consumer and supplier.

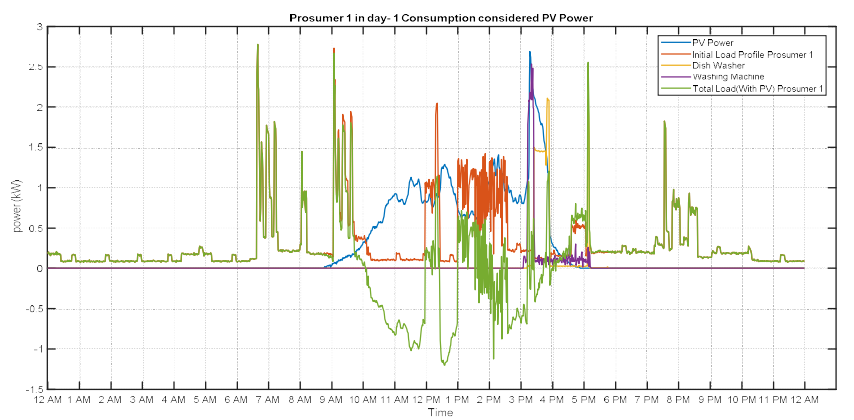

(a)

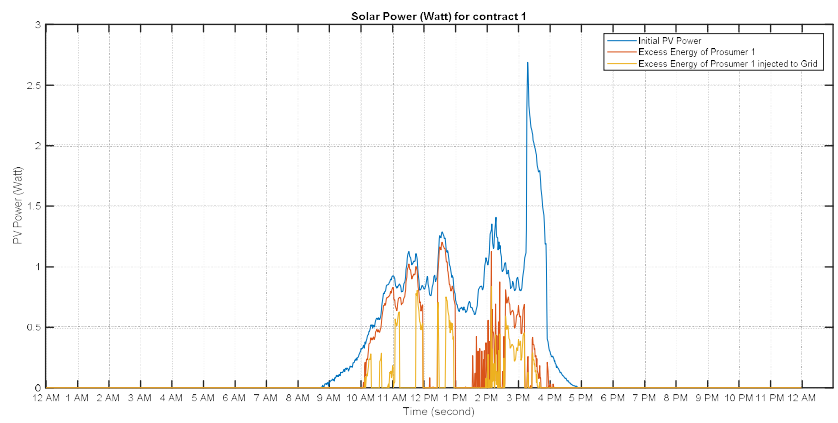

(b)

Figure 4. PSO result for contract 1 in day-1

Based on sharing of excess energy with partner contract in Fig. 5, generally, Using load shifting (LS) full optimization in bilateral contract, prosumer will increase their revenue in comparison with bilateral contract without LS. For example, prosumer 1 (CBW) using full optimization for their load shifting increases the revenue amount $10.28 \%$ than prosumer without load shifting.

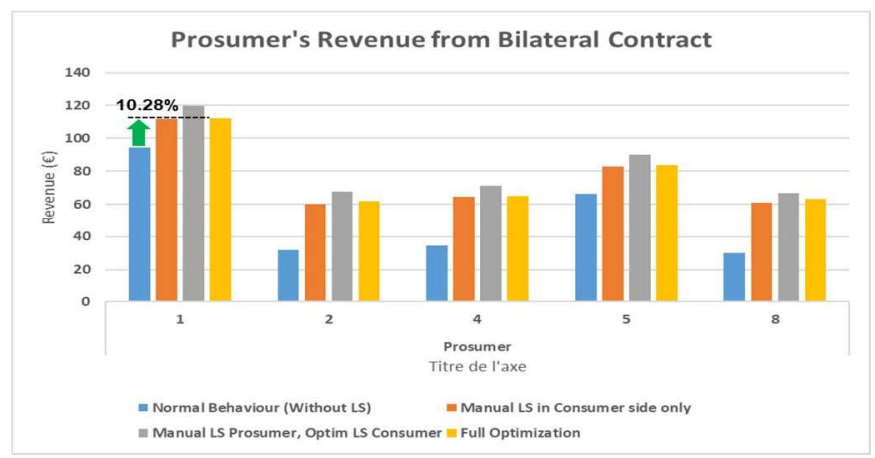

Figure 5. Prosumers revenue when they sell to the Supplier

Nevertheless, the revenue full optimization is less $6.31 \%$ than manual LS in prosumer and optimization in consumer method. The main reason is that the position of activating appliances in prosumer were not optimal in manual load shifting case. So that, excess energy that is sent to consumer greater than the bilateral contract using full optimization. 
Meanwhile, Comparison of cost accordance with four methods are produced as follow in fig. 6. In the normal consumption (without load shifting), prosumer CBW should pay their consumption to the supplier amount $348 €$ per year. Compared with manual LS that only applied in prosumer with optimization in consumer side, the cost is $276 €$ per year. However, when the full optimization is applied, prosumer only pay their energy from supplier amount $267 €$ per year. In percentage, Prosumer reduce their cost until $23.24 \%$ than without load shifting and in consumer RNCW, they reduce their consumption cost until $20.67 \%$.

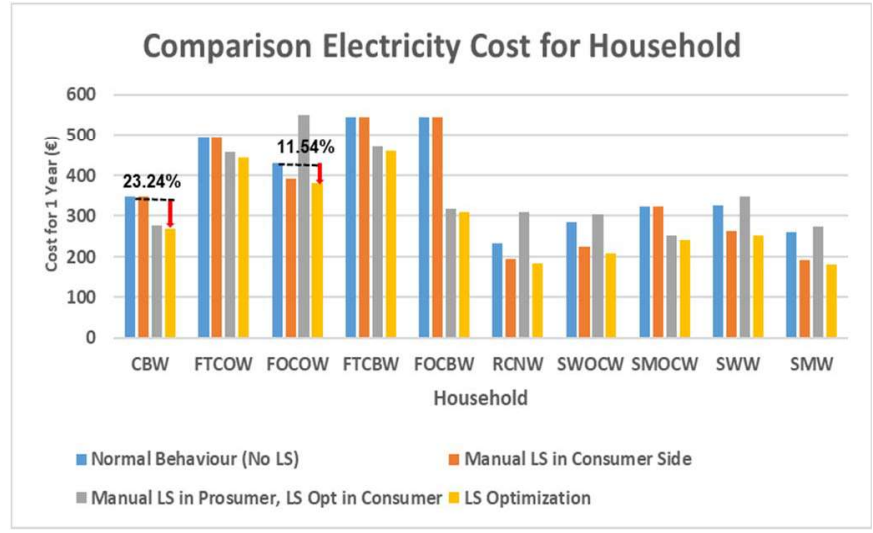

Figure 6. Comparison electricity cost among the households without LS and optimization, using LS without optimization and LS with optimization.

With PSO, the activating time of controlled appliance is applied. In the contract 1, household CBW as prosumer, they will activate their washing machine at 15:04 and dish washer at 15:11 in the first day. Meanwhile, the household FOCOW as consumer activate their washing machine at 12:20 and dish washer at 11:01. The others are showed at table 3 .

TABLE III. ACTIVATING TIME OF CONTROLLED APPLIANCES AFTER OPTIMIZATION AT DAY-1

\begin{tabular}{|c|c|c|}
\hline \multirow{2}{*}{ Household } & \multicolumn{2}{|c|}{ Activating Time } \\
\cline { 2 - 3 } & Washing Machine & Dishwasher \\
\hline CBW & $15: 04$ & $15: 11$ \\
\hline FTCOW & $12: 20$ & $15: 02$ \\
\hline FOCOW & $12: 20$ & $11: 01$ \\
\hline FTCBW & $11: 17$ & $12: 11$ \\
\hline FOCBW & $12: 15$ & $15: 03$ \\
\hline RCNW & $11: 18$ & $13: 51$ \\
\hline SWOCW & $11: 18$ & $13: 51$ \\
\hline SMOCW & $13: 57$ & $15: 02$ \\
\hline SWW & $11: 31$ & $13: 39$ \\
\hline SMW & $14: 11$ & $13: 21$ \\
\hline
\end{tabular}

VI. CONCLUSION

The differences between the methods presented above have emerged. Using PSO optimization, prosumer could maximize their self-consumption. As result, their cost is decreased rather than other methods and gain their revenue from sharing energy. Meanwhile, in consumer side, they also obtain the shared energy price cheaper than supplier price, where they save their money.

In future work, we will consider the battery storage system and more controlled appliance. The minimum cost and sharping of household satisfaction both prosumer and consumer is considered.

\section{ACKNOWLEDGMENT}

Riset-Pro Scholarship (World Bank Loan No. 8245-ID), Ministry of Science, Technology and Higher Education, Republic of Indonesia and CEA-INES support this work.

\section{REFERENCES}

[1] D. Zhang, N. Shah, and L.G Papageorgiou, "Efficient Energy Consumption and Operation Management in A Smart Building with Microgrid," Science Direct Energy Conversion and Management 74, pp. 209-222, 2013.

[2] R. Luthander, J. Widen, D. Nilsson, and J. Palm, "Photovoltaic selfconsumption in building: A review", Applied Energy 142, Elsevier 2015, Pages: $80-94$.

[3] G. Masson, J.I Briano, and M.J. Baez, "Review and Analysis of PV SelfConsumption Policies," IEA-PVPS., Switzerland, Tech. Rep. IEA-PVPS T1-28, 2016, [Online]. Available IEA-PVPS web site: http://www.ieapvps.org/index.php?id=382.

[4] Rehman Zafar, Anzar Mahmood, Sohail Razzaq, Wamiq Ali, Usman Naeem, Khurram Shehzad, 2017, "Prosumer based energy management and sharing in smart grid", Renewable and Sustainable Energy Reviews (2017), Elsevier, Pages 1675-1684.

[5] S. Yoshizawa, A. Yoshida, S. Kawano, Y. Fujimoto, Y. Amano, and Y. Hayashi, "Evaluation of coordinated energy management system for grid and home in distribution system with PVs", Journal of International Council on Electrical Engineering, Vol. 6 No.1, 2016, Pages: 126133, DOI: $10.1080 / 22348972.2016 .1173786$.

[6] R. Verschae, T. Kato, T. Matsuyama, "Energy Management in Prosumer Communities: A Coordinated Approach", Energies, MDPI, DOI: 10.3390/en9070562, 2016.

[7] Mohammad Shakeri, Mohsen Shayestegan, Hamza Abunima, 2017, "An Intelligent System Architecture in Home Energy Management System (HEMS) for Efficient Demand Response in Smart Grid", Energy and Buildings 138 (2017), Elsevier, Pages: 154-164.

[8] L. Oriol, "Self-Consumption framework in France," unpublished. Presented at the OFATE conf. May 2018, [Online]. Available web site:https://energie-fr-de.eu/fr/manifestations/lecteur/conference-surlautoconsommation-photovoltaique-cadres-reglementaires-et-modelesdaffaires-785.html?file=files/ofaenr/02-

conferences/2018/180515_conference_pv_autoconsommation/Presentat ions/02 Louise Oriol MTES OFATE DFBEW.pdf.

[9] L. Yao, C. Lai and, W.H. Lim, "Home Energy Management System based on Photovoltaic System", IEEE International Conference on Data Science and Data Intensive Systems pp.644-650, 2015.

[10] Alpana Sinha, Mala De, 2016, "Load Shifting Technique for Reduction of Peak Generation Capacity Requirement in Smart Grid", IEEE International conference on Power Electronic, Intellegent Control and Energy Systems (ICPEICES-2016), ISBN: 978-1-4673-8587-9.

[11] Hiroshi Kawashima, Takekazu Kato, Takashi Matsuyama, 2013, "Distributed mode scheduling for coordinated power balancing", In Proceedings of the 2013 IEEE International Conference on Smart Grid Communications (SmartGridComm), Vancouver, BC, Canada, 21-24 October 2013; pp. 19-24.

[12] J. Kennedy and R. Eberhart, "Particle swarm optimization," in Proc. 1995 IEEE Int. Conf. Neural Networks, vol. 4, pp. 1942-1948.

[13] Pflugradt, N., Teuscher, J, Platzer, B., Schufft, W., 2013, "Analyzing Low-Voltage Grids using a Behaviour Based Load Profile Generator". International Conference on Renewable Energies and Power Quality 2013, Bilbao, ISSN: 2172-038X 